\title{
Evaluation of Importance of Sentences based on Connectivity to Title
}

\author{
Takehiko Yoshimi and Toshiyuki Okunishi \\ Takahiro Yamaji and Yoji Fukumochi \\ Software Business Development Center, SHARP Corporation \\ 492 Minosho-cho Yamatokoriyama Nara, Japan
}

\begin{abstract}
This paper proposes a method of selecting important sentences from a text based on the evaluation of the connectivity between sentences by using surface information. We assume that the title of a text is the most concise statement which expresses the most essential information of the text, and that the closer a sentence relates to an important sentence, the more important this sentence is. The importance of a sentence is defined as the connectivity between the sentence and the title. The connectivity between two sentences is measured based on correference between a pronoun and a preceding (pro)noun, and on lexical cohesion of lexical items. In an experiment with 80 English texts, which consist of an average of 29.0 sentences, the proposed method has marked recall of $78.2 \%$ and precision of $57.7 \%$, with the selection ratio being $25 \%$. The recall and precision values surpass those achieved by conventional methods, which means that our method is more effective in abridging relatively short texts.
\end{abstract}

\section{1 はじめに}

電子化テキストの急增などに伴い，近年，テキストか ら要点を拔き出す重要文選択技術の必要性が高まって きている。このような要請に現状の技術レベルで応え るためには，表層的な情報を有効に利用することが必 要である。これまでに提案されている表層情報に基づ く手法では，文の重要度の評価が主に，1) 文に占める 重要語の割合，2) 段落の冒頭，末尾などのテキスト中 での文の出現位置，3) 事実を述へた文，書き手の見解 を述べた文などの文種，4）あらかじめ用意したテン プレートとの類似性などの評価基準のいずれか，ある いはこれらを組み合わせた基準に基づいて行なわれる (Luhn, 1958；Edmundson, 1969；喜多壮太郎, 1987； 鈴木康広 and 杤内香次, 1988; 間瀬久雄 et al., 1989; Salton et al., 1994; Brandow et al., 1995; 松尾比呂志 and 木本晴夫, 1995; 佐藤円 et al., 1995; 山本和英 et al., 1995; Watanabe, 1996; Zechner, 1996; 仲尾由雄, 1997).

本稿では，表層的な情報を手がかりとして文と文の つながりの強さを評価し，その強さに基づいて文の重 要度を決定する手法を提案する。提案する手法では文
の重要度に関して次の仮定を置く。

1. 表題はテキスト中で最も重要な文である.

2. 重要な文とのつながりが強ければ强いほど，その 文は重要である。

表題は，テキストの最も重要な情報を伝える表現で あるため，それだけで最も簡潔な抄録になりえるが， 多くの場合，それだけでは情報量が十分でない．従っ て，不足情報を補う文を選び出すことが必要となる が，そのような文は，表題への直接的なつながり，あ るいは他の文を介しての間接的なつながりが強い文で あると考えられる。このような考え方に基づいて，本 稿では, 文から表題へのつながりの強さをその文の重 要度とする，文と文のつながりの強さを評価するため に，次の二つの現象に着目する.

1. 人称代名詞と先行 (代) 名詞の前方照応

2. 同一辞書見出し語による語魚的なつながり

重要文を選択するために文間のつながりを解析する 従来の手法としては，1) 接続表現を手がかりとして修 辞構造を解析し，その結果に基づいて文の重要度を評 価する手法 (間瀬久雄 et al., 1989; Ono et al., 1994) や，2) 本稿と同じく，語彙的なつながりに着目した手 法 (Hoey, 1991; Collier, 1994; 福本㳯一, 1997; 佐々木 一朗 et al., 1993) がある. 文と文をつなぐ言語的手段 には，照応，代用，省略，接続表現の使用，語彙的な つながりがある (Halliday and Hasan, 1976)が，接続 表現の使用頻度はあまり高くない.このため，前者の 手法には，接続表現だけでは文間のつながりを解析す るための手がかりとしては十分でないという問題点が ある. 後者の手法では, 使用頻度が比較的高い照応を 手がかりとして利用していない。

\section{2 文の重要度の評価}

\section{1 テキスト構造と文の重要度に関する仮定}

本稿では，テキストを構成する文 $S_{1}, S_{2}, \cdots, S_{n}$ の間 で次の条件が成り立つと仮定する。

1. 冒頭文 $S_{1}$ はどの文にもつながらない.

2. $S_{1}$ 以外の各文 $S_{j}$ について， $S_{j}$ が直接つながる先 行文 $S_{i}(i<j)$ が唯一つ存在する.

この仮定は，二つの文 (の構成要素) のつながりに，後 続文 (の構成要素) から先行文 (の構成要菜) への方向 性があることを意味する．また，この仮定に従えば， 文が同時に複数の先行文に直接つながることはないの 


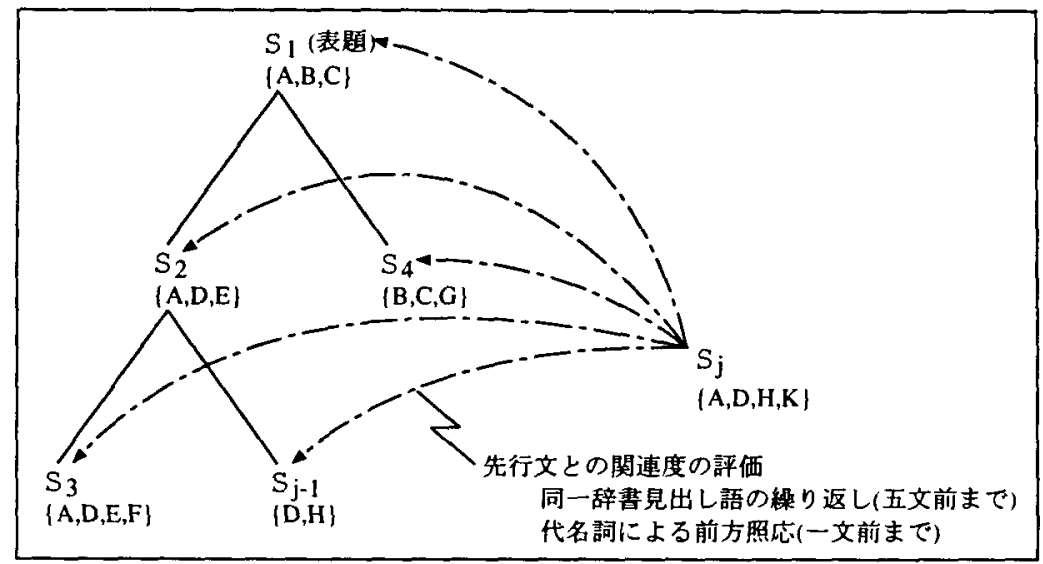

図 1: 文の重要度の評価

で，図 1 に示すように，テキスト構造は冒頭文 $S_{1}$ を根 節点とする木で表される。

1節で述べた基本的な考え方は次のように具体化で きる。

1. テキストの冒頭文 $S_{1}$ は，多くの場合，そのテキス トの表題であるので, $S_{1}$ にはテキスト全体で最大 の重要度を与える.

2. 冒頭文 $S_{1}$ 以外の文 $S_{j}$ の重要度は $S_{j}$ から先行文 $S_{i}$ へのつながりの強さ (関連度) と $S_{i}$ の重要度によっ て決まると考え，文 $S_{j}$ の重要度を求める式を次の ように定める.

$$
S_{j} \text { の重要度 }=\max _{i<j}\left\{S_{i} \text { の重要度 } \times S_{i} \text { と } S_{j} \text { の関連度 }\right\}
$$

文の重要度を (1) 式で求めることにすると, テキスト の冒頭から順に処理を行なっていけば，テキストを構 成する文すべての重要度が決定できるが，そのために は，まず，二つの文の関連度をどのようにして求める かを定めなければならない。

\section{2 二文間の関連度の評価}

提案手法への入力はテキストの形態素解析結果であ る. 形態素解析によって，テキスト中の各語の辞書見 出し語と品詞が得られる. 今回利用した形態素解析 系からの出力では，品詞は一意に決定されている．以 降, 品詞が名詞, 人称代名詞, 動詞, 形容詞, 副詞の いずれかである辞書見出し語を重要語と呼ぶ。

文 $S_{j}$ の先行文 $S_{i}$ へのつながりの強さ (関連度)を 求める式を次のように定める。

$$
S_{i} \text { と } S_{j} \text { の関連度 }=\frac{M_{i, j}}{N_{i}}
$$

ここで, $M_{i, j}$ は文 $S_{j}$ 中の重要語のうち先行文 $S_{i}$ の 題述 (rheme) 中の重要語につながるものの重みの和を 表し， $N_{i}$ は先行文 $S_{i}$ の題述中の重要語の数を表す.

(2) 式の意味は 2.2 .1 節以降で説明する. 二つの重要 語の間につながりがあるかどうかの判定は，人称代名 詞と先行 (代) 名詞の前方照応を検出すること (2.2.1 節) と，同一辞書見出し語による語氣的なつながりを検出
すること (2.2.2節)によって行なう。重要語への重み 付けについては 2.2.3節で述べ, 本稿でいう文の題述 の定義は 2.2 .4 節で与える.

\subsection{1人称代名詞と先行 (代) 名詞の照応の検出}

人称代名詞と先行名詞または先行代名詞との照応 を検出するためには，両者の人称，性，数，意味素性 をそれぞれ照合する必要がある。しかし，今回は，名 詞の性と意味菜性が記述されていない辞書を用いたの で, 照応の検出は両者の人称，数をそれぞれ照合する ことによって行なった。

しばしば指摘されるように，代名詞との間で照応 が成り立つ先行 (代) 名詞は，その代名詞を含む文 $S_{j}$ あるいは $S_{j}$ の直前の文 $S_{j-1}$ に現れることが多いの で, 先行 (代) 名詞の検索対象文を $S_{j}$ と $S_{j-1}$ に限定 する。検索は $S_{j}, S_{j-1}$ の順で行ない, $S_{j}$ 中の(代) 名詞との照合が成功した場合は， $S_{j-1}$ に対する処理 は行なわない。

\subsection{2 重要語の語集的なつなかりの検出}

二つの文に現机る重要語が文字列として一致する とき，両者の間に語彙的なつながりがあるとみなす。 文字列照合において，照合対象が両方とも笚語である 場合は，二つの重要語が完全に文字列一致したときに 限り照合成功とみなすが，照合対象の両方またはいず れか一方が(辞書に登録されている)連語である場合 は，二つの重要語が前方一致または後方一致したとき も照合成功とみなす。例えば, “put pressure on” “put”は前方一致で, “cabinet meeting”と“meeting”は後方一致で照合が成功する。

二つの文がある一定の距離以上離れていると，それ らに含まれる重要語の文字列照合が成功しても二つの 文の間に直接的なつながりはないと考えられる。この ため, 二文間の距離に関して制限を設ける。提案手法 を開発する際に訓練用として用いた英文テキスト 20 編 において，文字列照合が成功する重要語(人称代名詞 は除く)を含む二つの文の間の距雄と，その重要語が 二つの文を直接つなぐ役割を実際に果たしているかど うかとの関連を調べた結果に基づいて，処理範囲を文 $S_{j}$ から五文前までの先行文 $S_{i}(j-5 \leq i<j)$ とす 
る.

直観的には，単に処理対象範囲を制限するだけでな く, 文字列照合が成功する重要語を含む二文間の距離 に応じて照合結果に重み付けを行なう方が自然かもし れない、このため, 訓練テキストを対象とした実験に おいて, 文 $S_{j}$ から五文前までの先行文 $S_{i}$ の籍囲で, 二つの文の距離が離れるにつれてつながりの強さが弱 まるように重み付けを試みた。しかし，重み付けを行 なわない場合の再見率と適合率を上回る結果は得られ なかった。このため, 本稿では処理範囲を制限するに 留める.

\subsection{3 表題語への重み付け}

テキストの表題中に現れる重要語 (以降，表題語と 呼ぶ)は，そのテキストにおいて重要な情報を伝える と考えられる. 従って, 表題語を含む文の重要度を大 きくするために, 他の重要語に与える重みの值よりも 大きな值を与える (Edmundson, 1969; 閒瀬久雄 et al., 1989; Watanabe, 1996) のが適切である. 本稿では, 表題語に対する重み付けを行なう際にテキスト中での 表題語の出現頻度を考愿する。すなわち次のような仮 定を置く，表題語を含む文の重要性は, 表題語がテキ スト中に頻繁に現れる場合は, 表題語を含まない文の 重要性に比べて特に高いわけではないが，表題語がテ キスト中に希にしか現れない場合には，表題語を含ま ない文に比べて特に高くなる．訓練テキスト 20 編を分 析した結果に基づいて，表題語を含む文の数がテキス トの総文数の $1 / 4$ 以下である場合に限り，表題語の重 みをu(>1)とする. 表題語以外の重要語の重みは常 に1とする.

重要語kwの重み $= \begin{cases}w(>1) & k w \text { が表題語であり } \\ & \text { かつ } k w \text { を含む文の数 } \\ & \text { が総文数の } 1 / 4 \text { 以下の } \\ & \text { 場合 } \\ 1 & \text { その他 }\end{cases}$

重みwの具体的な値は, 訓練テキストを対象とした実 験で再現率と適合率ができるだけ高くなるように調整 し，最終的に $w=5$ とした.

\subsection{4 先行文の題述へのつながり}

テキストは, 通常, 先行文 $S_{i}$ における題述 (rheme) が文 $S_{j}$ においてその主題 (theme) として受け継がれ, それに新たな情報が付け加わるという形で展開する (Givon, 1979). 従って, 文 $S_{j}$ の先行文 $S_{i}$ へのつなが りの強さの評価を, $S_{j}$ が $S_{i}$ の題述をどれだけ多く主 題として受け継いでいるかに基づいて行なう.

主題と題述は, 文の前半部分が主題, 後半部分が題 述というように文中の位置で区別されることが多い (福地㢣，1985)が，本稿では，文中の位置ではなく, 関連文とのつながりに基づいて区別する。ここで， $S_{j}$ の関連文とは, 2.1 節の $(1)$ 式において, $\left\{S_{i}\right.$ の重要 度 $\times S_{i}$ と $S_{j}$ の関連度 $\}$ の值が最大となるときの先行 文 $S_{i}$ 意味する. この值を最大にする先行文が複数存 在する場合は， $S_{j}$ との距離が最も近いものを関連文と 呼ふ。関連文とのつながりに基づいて，主題と題述を 次のように定める. 文 $S_{j}$ の主題は， $S_{j}$ 中の重要語の うち $S_{j}$ の関連文中の重要語につながるものから構成さ れ, 文 $S_{j}$ の題述は, つながらない重要語から構成され
る.ただし，関連文を持たない冒頭文 $S_{1}$ では，それに 含まれる重要語すべてが題述を構成する，例えば，図 1 において，括胍 $\{$ と\}で括った英大文字を各文に現 れる重要語とすると, 各文の主題と題述は表 1 のよう に分けられる.

表 1: 図1の各文の主題と題述

\begin{tabular}{|c|c|c|c|}
\hline 文 & 関連文 & 主題 & 題述 \\
\hline$\overline{\overline{S_{1}}}$ & - & $=$ & $\overline{\mathrm{A}, \overline{\mathrm{B}}, \mathrm{C}}$ \\
\hline$S_{2}$ & $S_{1}$ & & $\mathrm{D}, \mathrm{E}$ \\
\hline$S_{3}$ & $S_{2}$ & $\mathrm{~A}, \mathrm{D}, \mathrm{E}$ & F \\
\hline$S_{4}$ & $S_{1}$ & $\mathrm{~B}, \mathrm{C}$ & $\mathrm{G}$ \\
\hline$S_{j-1}^{:}$ & $\dot{S}_{2}$ & $\mathrm{D}$ & H \\
\hline
\end{tabular}

\section{3 実験と考察}

提案手法の評価には，訓練テキストとは異なる英文テ キスト 80 編を用いた。評価テキストの総文数は，最も 短かいもので 12 文, 最も長いもので 64 文, 一テキス ト当たりの平均では 29.0 文であった．各テキストにつ いて，第三者によって重要と判断された文を，選択す べき正解文とした．正解文の数は，平均で元テキスト の総文数の $17.9 \%$ であった。

まず，各テキストについて，正解文と同じ数だけ 文を選択するように設定して重要文選択実験を行なっ た。この場合の精度 (再現率と適合率は同じ值となる) は， $72.3 \%$ であった．各テキストごとの精度分布を図 2 に示す。

文選択率を $5 \%$ から $100 \%$ まで五刻みで変化させた ときの平均再現率と平均適合率の変化の様子を図 3 に 示す。図 $3 に は$, 精度比較のために実装した重要語密 度法に上る実験結果を併せて示す。重要語密度法に関 して改良手法が提案されている (鈴木康広 and 杤内香 次, 1988)が,ここでは次式で文 $S$ の重要度を評価し た.

$$
\text { 文 } S \text { 重要度 }=\frac{F}{N}
$$

ここで, $F$ は文 $S$ 中の各重要語のテキスト全体での出 現頻度の和を表し， $N$ は文S 中の重要語の数を表す。 図3に上れば，適切な文選択率であるとされる $20 \%$ か ら $30 \%$ までの付近で, 特に, 提案手法の精度が重要語 密度法の精度を大きく上回っている。

提案手法の精度と、インターネット上で試用可能な システムA，市販されている三つのシステム B， C, Dの精度を比較した．それぞれの平均再現率と平均 適合率を表 2 に示す. システム A， B， C，D文選 択率は，各システムの既定状態で選ばれた文の数とテ キストの総文数から逆算したものである.提案手法の 文選択率は, 四システムの文選抧率とほぼ同じである $25 \%$ とした. 表 2 によれば，一般ユーザに利用されて いる実働システムの精度を提案手法の精度が上回って おり，提案手法の実用的な抄録システムとしての有効 性が示されている。

提案手法によって正解文に与えられた重要度が小 さく，正解文が選択されなかった原因を分析した。こ 


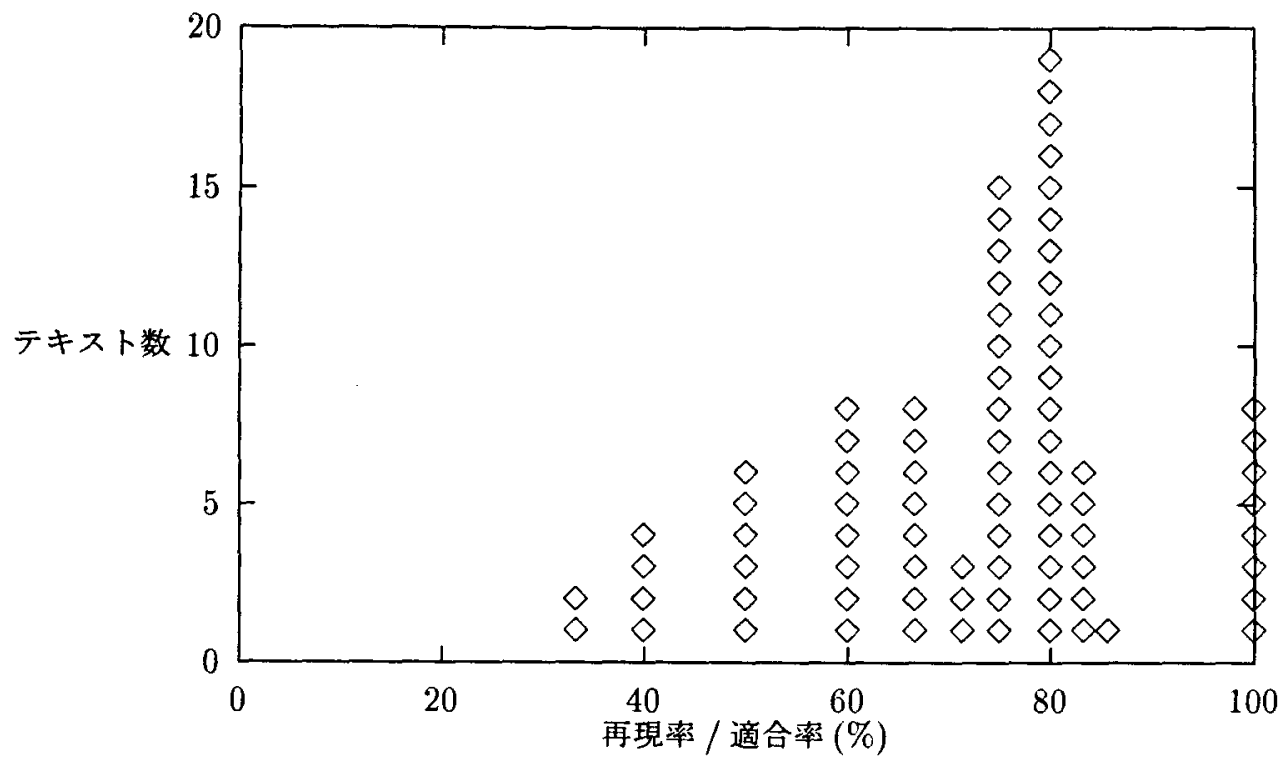

図 2：提案手法による精度分布

表 2: 提案手法と他の実働システムの精度比較

\begin{tabular}{|c||c|r|r|}
\hline & 再現率 & 適合率 & 文選択率 \\
\hline \hline 提案手法 & $78.2 \%$ & $57.7 \%$ & $25 \%$ \\
システム $\mathrm{A}$ & $72.3 \%$ & $52.6 \%$ & $26 \%$ \\
システム & $61.7 \%$ & $39.5 \%$ & $29 \%$ \\
システム C & $61.4 \%$ & $40.9 \%$ & $29 \%$ \\
システム D & $57.5 \%$ & $42.2 \%$ & $27 \%$ \\
\hline
\end{tabular}

こでは代表的な原因を二つ挙げる。一つは，辞書見出 し語の文字列照合では，語裹的なつながりが捉えられ なかったことである、あるテキストでは, "shooting” と “gunfire”の類義関係が把握できないため, "gunfire”を含む正解文はどの先行文にもつながらないとみ なされ，重要文として選択できなかった。このような 語奥的なつながりを捉えるためにはシソーラスが必要 となるが，他のテキストでは，辞書見出し語の文字列 照合の代わりに語基 (base) の文字列照合を行なえば, つながりが捉えられる可能性もあった。例えば, “announce" と “announcement” は, 辞書見出し語として は異なるが語基は同一であるので，文字列照合が成功 するだろう。

本研究では，一般ユーザに利用される実働システム への組み込みを前提として，高速な処理を実現するこ とを目標の一つとした. 実働システムでは, プロトタ イプシステムと異なり，重要文選択の精度と共に処理 速度も重要視される。シソーラスの検索に比べて，文 字列照合は処理効率の点で有利である.

正解文に十分大きい重要度が与えられなかったもう 一つの原因は，テキストが複数のサブトピックから構 成されていることであった。一般に，トピックが切り 替わると，それまでとは異なった語彙が用いられるよ
うになる。このため，提案手法のように語彙的なつな がり(と人称代名詞による前方照応)に基づいて文と 文のつながりを評価する手法では，トピックが切り替 わる文から先行文へのつながりが弱いと判定され，卜 ピック切り替わり文に対して与えられる重要度は小さ くなる. 従って, トピック切り替わり文が正解文であ るようなテキストでは，高い精度を得ることが難しく なる。

\section{4 おわりに}

本稿では，人称代名詞による前方照応と，同一辞書見 出し語による語異的なつながりを検出することによっ て，テキストを構成する各文と表題との直接的なつな がり，あるいは他の文を介しての間接的なつながりの 強さを評価し，その強さに基づいて各文の重要度を決 定する手法を提案した。平均で 29.0 文から成る英文テ キスト 80 編を対象とした実験では，文選択率を $25 \%$ に設定したとき，再現率 $78.2 \%$ ，適合率 $57.7 \%$ の精度 を得, 提案手法が比較的短いテキストに対して有効で あることを確認した。

複数のサブトピックから成るような比較的長いテキ ストの扱いは今後の課題である。同一辞書見出し語の 出現頻度と分布を利用してトピックの切り替わりを検 出し (Hearst，1997), 各サブトピックごとに提案手法 を適用すると、長いテキストに対してどの程度の精度 が得られるかを今後検証したい。

\section{References}

R. Brandow, K. Mitze, and L. F. Rau. 1995. Automatic Condensation of Electric Publications by Sentence Selection. Information Processing \&: Management, 31(5):675-685. 


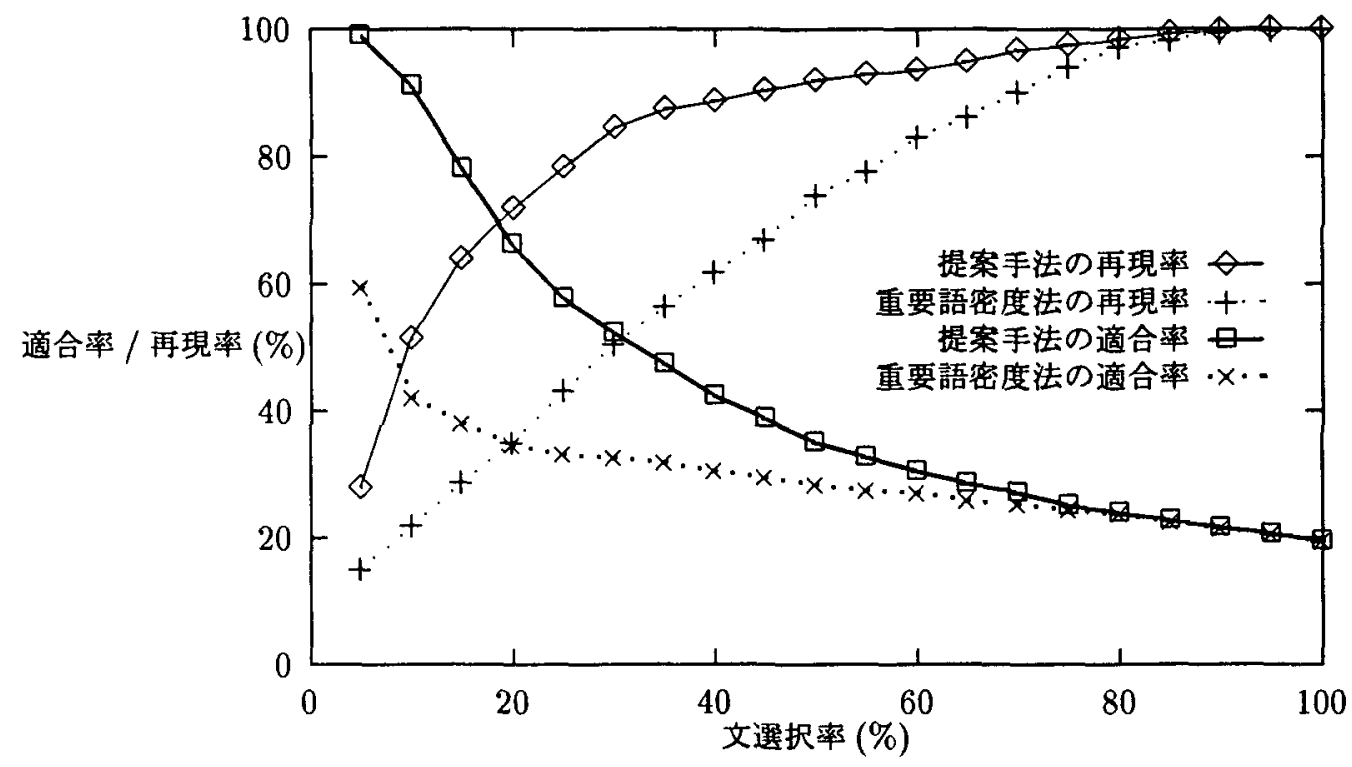

図 3: 提案手法と重要語密度法の精度比較

A. Collier. 1994. A System for Automating Concordance Line Selection. In Proceedings of NeMLaP, pages 95-100.

H. P. Edmundson. 1969. New Methods in Automatic Extracting. Journal of the $A C M$, 16(2):264-285.

T. Givon. 1979. From Discourse to Syntax: Grammar as a Processing Strategy. In T. Givon, editor, Discourse and Syntax, pages 81-112. Academic Press.

M. A. K. Halliday and R. Hasan. 1976. Cohesion in English. Longman.

M. A. Hearst. 1997. TextTiling: Segmenting Text into Multi-paragraph Subtopic Passages. Computational Linguistics, 23(1):33-64.

M. Hoey. 1991. Patterns of Lexis in Text. Describing English Language. Oxford University Press.

H. P. Luhn. 1958. The Automatic Creation of Literature Abstracts. IBM Journal for Research and Development, 2(2):159-165.

K. Ono, K. Sumita, and S. Miike. 1994. Abstract Generation based on Rhetorical Structure Extraction. In Proceedings of COLING, pages 344-348.

G. Salton, J. Allan, C. Buckley, and A. Singhal. 1994. Automatic Analysis, Theme Generation, and Summarization of Machine-Readable Texts. Science, 264(3):1421-1426.

H. Watanabe. 1996. A Method for Abstracting Newspaper Articles by Using Surface Clues. In Proceedings of COLING, pages 974-979.
K. Zechner. 1996. Fast Generation of Abstracts from General Domain Text Corpora by Extracting Relevant Sentences. In Proceedings of COLING, pages 986-989.

間瀬久雄, 大西昇, and 杉江昇. 1989. 説明文の抄録作 成について. NLC89-40, 電子情報通信学会.

喜多壮太郎．1987．説明文を要約するシステム．NL636 , 情報処理学会.

佐々木一朗, 增山繁，and 内藤昭三.1993. 語彙的結束 性に着目した文章抄録法の提案. NL98-9，情報処理 学会.

佐藤円，佐藤理史， and 篠田陽一，1995．電子ニュー スのダイジェスト自動生成. 情報処理学会論文誌, 36(10):2371-2379.

山本和英, 增山繁, and 内藤昭三. 1995. 文章内構造を 複合的に利用した論説文要約システムGREEN. 自 然言語処理, 2(1):39-55.

松尾比呂志 and 木本晴夫. 1995. 抽出パターンの階 層的照合に基つく日本語テキストからの内容抽出法. 情報処理学会論文誌, 36(8):1838-1844.

仲尾由雄. 1997. 見出しを利用した新聞・レポートか らのダイジェスト情報の抽出．NL117-17，情報処理 学会.

福地筆. 1985. 談話の構造. 大修館書店.

福本淳一. 1997. 文の結合度に基つく内容抽出法. In 言 語処理学会第 3 回年次大会発表論文集, pages 321324.

鈴木康広 and 杤内香次. 1988. キーワード密度方式自 動抄録法の改良一高頻度隣接語による改善 一. 情 報処理学会論文誌, $29(3): 325-328$. 